\title{
Social Intelligence, Emotional Intelligence and the Therapeutic Relationship among Clinical Occupational Therapist
}

\author{
Smily Jesu Priya Victor Paulraj ${ }^{1,2}$, Shahad Fahad Alaboudi, ${ }^{1,2}$, \\ Raniah Mansour Mali ${ }^{1,2}$, Feryal Ahmad Ezzi ${ }^{1,2}$, Luluh Musaad Alawad ${ }^{1,2}$, \\ Saba Abdullah Alqahtani ${ }^{1,2}$, Jayachandran Vetrayan ${ }^{1,2}$ \\ ${ }^{1}$ Occupational Therapy Program, College of Applied Medical Sciences - King Saud bin Abdulaziz University \\ for Health Sciences, Riyadh, Kingdom of Saudi Arabia \\ ${ }^{2}$ King Abdullah International Medical Research Center (KAIMRC), Riyadh, Kingdom of Saudi Arabia
}

Corresponding Author: Smily Jesu Priya Victor Paulraj

\begin{abstract}
Social and emotional intelligence has understood their own and other's feelings and reactions according to their needs. The therapeutic relationship, which considered as a foundational concept among occupational therapy practitioners, which refers to establish rapport with the patient and the therapist to understand the patient's needs and set the goal respectively. To determine the relationship between social intelligence (SI), emotional intelligence (EI) and therapeutic relationship (TR) among clinical occupational therapists. The study used quantitative non-experimental correlational design. Eighty participants recruited from eight hospitals in Riyadh. Data conducted using a closed-ended questionnaire. It contains several questions in social intelligence (MESI), emotional intelligence (Assessing emotional scale), and therapeutic relationship between them (STAR). The questionnaire distributed to clinical occupational therapists in the form of an electronic questionnaire to facilitate the data collection process. The results releveled that there was a significant relationship in social intelligence, emotional intelligence and therapeutic relationship among clinical occupational therapists $(\mathrm{p}=<0.05)$. Future study needs to provide the awareness of social intelligence, emotional intelligence and therapeutic relationship among clinical occupational therapist.
\end{abstract}

Keywords: social intelligence, emotional intelligence, therapeutic relationship, clinical occupational therapist

\section{INTRODUCTION}

Social intelligence (SI) is the capability to understand and manage people to act wisely in a human relationship (John \& Mayer, 2009). When someone is using the knowledge of the present to improve the future by finding the best pathway. Moreover, it is more about understanding the personalities and reactive behaviors of people (Chou, 2016). Poor social intelligence would make the therapists tired of fatigue and lack of self-confidence and inability to communicate well with their clients and understand their needs would lead to poor relationships with their clients. SI required work, patience and understanding especially in the occupational therapy (OT) field (Chou, 2016). Furthermore, this intelligence was the possibility of individuals to get through life situations in general and complex OT cases in specific (John \& Mayer, 2009). Moreover, the possibility of the therapists to convince and adapt to their clients and in planning to reach the goals that they aimed to. Besides, they made every effort to 
Smily Jesu Priya Victor Paulraj et.al. Social intelligence, emotional intelligence and the therapeutic relationship among clinical occupational therapist.

achieve satisfaction in social relations with clients and achieve a balance between individuals and their social environment to satisfy personal and social needs; also, they listened effectively to build a constructive dialogue (Chou, 2016). More importance that is if the therapists apply all the above, it will help them to build up a great relationship with the clients which also would make clients committed to their plans.

The second aspect of this research was emotional intelligence (EI), which defined as "the ability to monitor one's own and others' feelings and emotions, to discriminate among them and to use this information to guide one's thinking and actions” (Jacuqui, Jo-anne, 2013). Emotional intelligence is a type of social intelligence that includes the ability to examine and assess one's own emotions and behaviors as well as those of others (Salovey \& Mayer, 1990). The main aspect of emotional intelligence was to understand how clinical occupational therapists observe, distinguish, and accomplish emotions in a challenge to forecast and help personal effectiveness (Cherniss, 2002). Self-emotional management conceded as the critical value in occupational practice (Ardito, Rabellino, 2011). Everyone possesses an emotional intelligence known as intrapersonal knowledge, which enables one to detect and symbolize complex and highly differentiated sets of feelings. One of the most important aspects of EI is that people differ in their ability to harness their own emotions to solve or deal with and adapt to problems. The importance of emotional intelligence was to be mindful of, express, and control one's feelings, also, with empathy and careful handling the interpersonal relationships. EI was the way to both individual and expert achievements, and entryway to a balanced life. (Duggal, 2019 \& Cherr, 2018). Poor emotional intelligence was an issue that could have sway on an assorted variety of social connections. The leading causes of low EI were unmotivated staff, deficiency of sleep, unexpected emotional outbursts, poor communication, lack of self-knowledge, and anxiety (Cherry, 2018). Besides, the effects of low EI would be less proactive when managing feelings, choices or potentially efficiency, lack of empathy, poor performance, negative emotions lead to behavioral issues, and less confident and trusting anxiety (Cherry, 2018).

The final aspect of this research was the therapeutic relationship which considers as a foundational concept among occupational therapy practitioners. A therapeutic relationship or therapeutic alliance defined as "a non-neurotic and nontransferential relational component established between patient and therapist which allows the patient to follow the therapist and use his or her interpretations" (Peloquin, 1990). It began to develop from the very first consultation and continues through the treatment sessions. In occupational therapy, the patient-therapist relationship has been focusing over the years on the combination of competence and caring (Pendleton \& Schultz-Krohn, 2006). Due to the high effectiveness of managing the therapeutic relationship on successful treatment, it was as important as understanding the theory and technique of treatment. From observing TR, we could predict whether therapy would be successful or not. Moreover, this relationship causes a significant difference in the patients' experience because it includes the agreement of the therapist and patient with each other on treatment tasks and goals. (Petrides \& Furnham, 2001; Petrides \& Furnham, 2003; Petrides, Niven, \& Mouskounti, 2006; Petrides, Pita, \& Kokkinaki, 2007; Petrides, 2009). The establishment of a viable therapeutic relationship enhances the therapist's interaction with clients and directs the intervention to be client-centered (Pendleton \& Schultz-Krohn, 2009). Poor TR causes difficulties or misunderstandings between therapist and patient. (Muran \& Barber, 2010, Fedders, 2008) As a result, patients may stop the treatment, change the therapist, 
Smily Jesu Priya Victor Paulraj et.al. Social intelligence, emotional intelligence and the therapeutic relationship among clinical occupational therapist.

or may not follow the therapist's instructions. Therefore, the quality of the therapeutic relationship was critical to treatment success.

The importance of social intelligence and emotional intelligence in clinical performance was evident (Birks \& Watt, 2007; Akerjordet, \& Severinsson, 2007). The social intelligence, emotional intelligence and therapeutic relationship with the client were essential during screening, evaluation, goal setting and OT treatment implementation of clinical Occupational Therapists. It was crucial to understand the clinical occupational therapist's socioemotional intelligence and therapeutic relationship with the client while providing OT service. However, the lack of previous studies to examine the relationship between socio-emotional intelligence and therapeutic relationship among clinical occupational therapist in Riyadh, Saudi Arabia.

Hence, the purpose of the current study was to explore the ability of the occupational therapist to act thankfully in the human relationship due to understanding others' feelings and emotions and its association with their relationship with their patient which facilitates the therapy. Therefore, the study aimed to examine the relationship between social intelligence, emotional intelligence and therapeutic relationship among clinical occupational therapist. The specific objectives were to i) identify the social intelligence, emotional intelligence among clinical occupational therapists, ii) identify the therapeutic relationship among clinical occupational therapists, iii) find the relationship between social intelligence, emotional intelligence and therapeutic relationship among clinical occupational therapist. The secondary objective was to find relationship between age, gender and years of experiences with SI, EI, and TR among clinical occupational therapist.

\section{METHODS}

The current study used quantitative non-experimental correlational design to investigate the relationship between social intelligence, emotional intelligence and therapeutic relationship among clinical occupational therapist. This study was focusing on the clinical occupational therapist and the effect of their socioemotional intelligence and therapeutic relation with patients/clients. The convenient sampling used for selecting the subject for the proposed study. The inclusion of the study was clinical occupational therapist, both gender with 25 to 55 years old and study excluded academic occupational therapist and interns. Prior to the study, we got approval from the institutional review board (IRB study number SP19/153/R) of King Saud bin Abdulaziz University for Health Sciences, King Abdullah International Medical Research Center (KAIMRC), Riyadh and obtain signed concern from the participants. The study conducted at the King Abdulaziz Medical City, Rehabilitation unit, and Occupational Therapy department in various medical hospitals and centers across Riyadh. The study duration was 3 months to collect data from questionnaire forms.

\section{Outcome Measures}

Trait Emotional Intelligence Questionnaire - The Assessing Emotions Scale is to measure emotional intelligent among occupational therapists. The Assessing Emotions Scale consists of 33 items rated. Closed-ended questions on a 5point scale ranging from 1 (strongly disagree) to 7 (strongly agree) with subscales of perception of emotions, managing emotions in the self, social skills or managing others, emotions, and utilizing emotion. Total scale scores calculated by summing all items. Scores can range from 33 to 165, with higher scores indicating more innate emotional intelligence (Petrides, 2009).

$\begin{array}{ccc}\text { Manipulation } & \text { Empathy } & \text { Social } \\ \text { Irritability (MESI) } & \text { measures } & \text { social }\end{array}$


Smily Jesu Priya Victor Paulraj et.al. Social intelligence, emotional intelligence and the therapeutic relationship among clinical occupational therapist.

intelligence of the clinical occupational therapist. It contains 21 items of closedended question evaluate on a 5-point scale (0-never, 4-very often) and its internal consistency (Cronbach's alpha) was 0.90 (Frankovsky \& Birknerova, 2014).

Scale to Assess the Therapeutic Relationship (STAR) - $C$ is a brief scale designed to assess TRs among occupational therapists with good psychometric qualities. This scale has 12 items and have three subscales. The total scores are obtained by summing the relevant subscale items as follows: Positive Collaboration: 1, 2, 5, 7, 10, 12, Emotional Difficulties: 4, 6, 9 and Positive Clinician Input: 3, 8, 11. Rate each item on the following scale: never $=0$, rarely $=1$, sometimes $=2$, often $=3$, always $=$ 4. Test-retest reliability was $r=0.76$ for STAR-P and $r=0.68$ for STAR-C (Mcguire- snieckus, Mccabe, Catty, Hansson, \& Priebe, 2006).

\section{Data Analysis}

The data collected entered in Microsoft Excel and transferred to SPSS version 22 for the statistical analysis. Tables used to represent the results. Data checked for normality using the Shapiro-Wilk test. Frequencies and percentages used for categorized variables. Continues variables were represented as mean and standard deviation (SD) if normally distributed, the median and interquartile range used if not normally distributed. Person correlation test used for the identify relationship between socio-emotional intelligence and the therapeutic relationship. A P value of $<0.05$ considered statistically significant.

\section{RESULT}

Table 1: Descriptive data

\begin{tabular}{|c|c|c|c|c|}
\hline \multirow[t]{2}{*}{ Years of experience of Clinical OT } & \multirow[t]{2}{*}{ No of participants } & \multirow[t]{2}{*}{ Age range (Mean \& SD) } & \multicolumn{2}{|c|}{ Gender } \\
\hline & & & Males & Females \\
\hline 6 years to 10 years & 4 & $31-35$ & - & 4 \\
\hline 15 years to 20 years & 1 & $41-45$ & - & 1 \\
\hline Total & 80 & Age (25 - 45 years, mean 28.28 \& SD= 3.5790) & 19 & 61 \\
\hline
\end{tabular}

The research sample consisted of 80 participants aged 25 to 45 years. The average mean age was 28.28 with a standard deviation of 3.57. The sample contained 61 females and 19 males. The research sample consisted of clinical occupational therapists in KSA, Riyadh, working in both private and public hospitals. The therapists' years of experience ranged from one month to twenty years. Table 1 illustrates descriptive data of research variables of years of experience of Clinical Occupational Therapist (OT), number of participants, age range, and gender.

Table 2 showed the frequency and percentage of emotional intelligence among the clinical occupational therapists. Assessing Emotional scale was used to find the emotional intelligence and it has four domains, perception of emotion, own emotion, utilization of emotions, and managing others' emotions, within 33 scaled questions ranging from 1-4. In the perception of Emotions domain which has ten questions of (Q5, Q9, Q15, Q18, Q19, Q22, Q25, Q29, Q32, Q33), none of the therapists strongly disagreed that he or she is aware of his or her emotions also they aware of their own non-verbal communication they send to others and understand the people emotions by observe their facial expression. Besides, they easily recognize their own emotions as they experience them and can tell how people are feeling by listening to the tone of their voice. Furthermore, more than $40 \%$ of them somewhat agreed about their awareness of their emotions as they experience them, recognition of the people' emotions are experiencing by looking at their facial 
Smily Jesu Priya Victor Paulraj et.al. Social intelligence, emotional intelligence and the therapeutic relationship among clinical occupational therapist.

expressions, knowledge of why their emotions change, awareness of the nonverbal messages other people send, knowing what other people are feeling just by looking at them, and recognition of people' feelings by listening to the tone of their voice. Next, in the second domain, has nine questions (Q2, Q3, Q10, Q12, Q14, Q21, Q23, Q28, Q31) which is Own Emotions, none of the therapists strongly disagreed that they are confident with their abilities in facing obstacles, doing well in challenges, and using good moods to help themselves keep trying in the face of obstacles. None of them also somewhat disagreed about having an awareness of the non-verbal messages they send to others. More than $50 \%$ of the therapists strongly disagreed that they give up when faced with a challenge because of the belief of failure. More than 45\% agreed that they somewhat agreed about expecting that they will do well on most tasks if they imagine a positive outcome. Above $42 \%$ were strongly agree that they expect good things to happen and seek out activities that make them happy. For the third domain that is utilization of emotions that contains six questions (Q6, Q7, Q8, Q17, Q20, Q27) it showed that none of the therapists strongly disagree about having a good mood enable them to come up with new ideas, most of the participants were somewhat agree and strongly agreed that emotions and good mood are associated with solving problems and coming up with new ideas. For the final domain in this scale, managing others' emotions, that has eight questions (Q1, Q4, Q11, Q13, Q16, Q24, Q26, Q30). According to the results of the study, none of the participants strongly disagreed that others find it easy to confide in them, and when someone tells them about a significant event in his or her life, they almost feel as if they witnessed the event themselves. 51.2\% of them strongly agreed about their knowledge of when it is appropriate to discuss personal issues with others. The highest percentage of agreement in this questionnaire is $61.3 \%$ which most of the participants were strongly agree that they complement others when they have done something well.

Table 2: Emotional intelligence among clinical occupational therapists

\begin{tabular}{|c|c|c|c|c|c|}
\hline $\begin{array}{ll}\text { Perception } & \text { of } \\
\text { Emotions } & \\
\end{array}$ & $\begin{array}{l}\text { Strongly } \\
\text { Disagree (1) }\end{array}$ & $\begin{array}{l}\text { Somewhat } \\
\text { Disagree (2) }\end{array}$ & $\begin{array}{l}\text { Neither Agree nor } \\
\text { Disagree (3) }\end{array}$ & $\begin{array}{l}\text { Somewhat Agree } \\
\text { (4) }\end{array}$ & $\begin{array}{l}\text { Strongly Agree } \\
(5)\end{array}$ \\
\hline Q5 & $20(25 \%)$ & $26(32.5 \%)$ & $15(18.75 \%)$ & $11(13.75 \%)$ & $8(10 \%)$ \\
\hline Q9 & $0(0 \%)$ & $5(6.25 \%)$ & $13(16.25 \%)$ & $38(47.5 \%)$ & $24(30 \%)$ \\
\hline Q15 & $0(0 \%)$ & $15(18.75 \%)$ & $11(13.75 \%)$ & $23(28.75 \%)$ & $31(38.75 \%)$ \\
\hline Q18 & $0(0 \%)$ & $3(3.75 \%)$ & $10(12.5 \%)$ & $34(42.5 \%)$ & $33(41.25 \%)$ \\
\hline Q19 & $2(2.5 \%)$ & $7(8.75 \%)$ & $20(25 \%)$ & $34(42.5 \%)$ & $17(21.25 \%)$ \\
\hline Q22 & $0(0 \%)$ & $9(11.25 \%)$ & $13(16.25 \%)$ & $35(43.75 \%)$ & $23(28.75 \%)$ \\
\hline Q25 & $0(0 \%)$ & $6(7.5 \%)$ & $14(17.5 \%)$ & $34(42.5 \%)$ & $26(32.5 \%)$ \\
\hline Q29 & $1(1.25 \%)$ & $8(10 \%)$ & $26(32.5 \%)$ & $36(45 \%)$ & $9(11.25 \%)$ \\
\hline Q32 & $0(0 \%)$ & $5(6.25 \%)$ & $16(20 \%)$ & $44(55 \%)$ & $15(18.75 \%)$ \\
\hline Q33 & $11(13.75 \%)$ & $34(42.5 \%)$ & $20(25 \%)$ & $11(13.75 \%)$ & $4(5 \%)$ \\
\hline Own Emotions & $\begin{array}{l}\text { Strongly } \\
\text { Disagree (1) }\end{array}$ & $\begin{array}{l}\text { Somewhat } \\
\text { Disagree (2) }\end{array}$ & $\begin{array}{l}\text { Neither Agree nor } \\
\text { Disagree (3) }\end{array}$ & $\begin{array}{l}\text { Somewhat Agree } \\
\text { (4) }\end{array}$ & $\begin{array}{l}\text { Strongly Agree } \\
\text { (5) }\end{array}$ \\
\hline Q2 & $0(0 \%)$ & $4(5 \%)$ & $8(10 \%)$ & $36(45 \%)$ & $32(40 \%)$ \\
\hline Q3 & $0(0 \%)$ & $3(3.75 \%)$ & $13(16.25 \%)$ & $44(55 \%)$ & $20(25 \%)$ \\
\hline Q10 & $2(2.5 \%)$ & $4(5 \%)$ & $16(20 \%)$ & $23(28.75 \%)$ & $35(43.75 \%)$ \\
\hline Q12 & $2(2.5 \%)$ & $20(25 \%)$ & $23(28.75 \%)$ & $28(35 \%)$ & $7(8.75 \%)$ \\
\hline Q14 & $1(1.25 \%)$ & $0(0 \%)$ & $13(16.25 \%)$ & $30(37.5 \%)$ & $36(45 \%)$ \\
\hline Q21 & $2(2.5 \%)$ & $17(21.25 \%)$ & $21(26.25 \%)$ & $24(30 \%)$ & $16(20 \%)$ \\
\hline Q23 & $2(2.5 \%)$ & $1(1.25 \%)$ & $10(12.5 \%)$ & $37(46.25 \%)$ & $30(37.5 \%)$ \\
\hline Q28 & $43(53.75 \%)$ & $20(25 \%)$ & $9(11.25 \%)$ & $6(7.5 \%)$ & $2(2.5 \%)$ \\
\hline Q31 & $0(0 \%)$ & $4(5 \%)$ & $15(18.75 \%)$ & $34(42.5 \%)$ & $27(33.75 \%)$ \\
\hline Utilization of Emotion & $\begin{array}{l}\text { Strongly } \\
\text { Disagree (1) }\end{array}$ & $\begin{array}{l}\text { Somewhat } \\
\text { Disagree (2) }\end{array}$ & $\begin{array}{l}\text { Neither Agree nor } \\
\text { Disagree (3) }\end{array}$ & $\begin{array}{l}\text { Somewhat Agree } \\
\text { (4) }\end{array}$ & $\begin{array}{l}\text { Strongly Agree } \\
\text { (5) }\end{array}$ \\
\hline Q6 & $0(0 \%)$ & $1(1.25 \%)$ & $5(6.25 \%)$ & $35(43.75 \%)$ & $39(48.75 \%)$ \\
\hline Q7 & $5(6.25 \%)$ & $6(7.5 \%)$ & $22(27.5 \%)$ & $33(41.25 \%)$ & $14(17.5 \%)$ \\
\hline Q8 & $2(2.5 \%)$ & $6(7.5 \%)$ & $18(22.5 \%)$ & $27(33.75 \%)$ & $27(33.75 \%)$ \\
\hline Q17 & $2(2.5 \%)$ & $2(2.5 \%)$ & $8(10 \%)$ & $36(45 \%)$ & $32(40 \%)$ \\
\hline Q20 & $0(0 \%)$ & $2(2.5 \%)$ & $10(12.5 \%)$ & $36(45 \%)$ & $32(40 \%)$ \\
\hline Q27 & $2(2.5 \%)$ & $8(10 \%)$ & $26(32.5 \%)$ & $36(45 \%)$ & $8(10 \%)$ \\
\hline
\end{tabular}


Smily Jesu Priya Victor Paulraj et.al. Social intelligence, emotional intelligence and the therapeutic relationship among clinical occupational therapist.

\begin{tabular}{|l|l|l|l|l|l|}
\hline \multicolumn{7}{|c|}{ Table 2 Continued... } \\
\hline $\begin{array}{l}\text { Managing Others' } \\
\text { Emotions }\end{array}$ & $\begin{array}{l}\text { Strongly } \\
\text { Disagree (1) }\end{array}$ & $\begin{array}{l}\text { Somewhat } \\
\text { Disagree (2) }\end{array}$ & $\begin{array}{l}\text { Neither Agree } \\
\text { Disagree (3) }\end{array}$ & $\begin{array}{l}\text { Somer } \\
(4)\end{array}$ \\
\hline Q1 & $2(2.5 \%)$ & $5(6.25 \%)$ & $4(5 \%)$ & $28(35 \%)$ & $41(51.25 \%)$ \\
\hline Q4 & $0(0 \%)$ & $6(7.5 \%)$ & $23(28.75 \%)$ & $23(28.75 \%)$ \\
\hline Q11 & $10(12.5 \%)$ & $14(17.5 \%)$ & $13(16.25 \%)$ & $28(35 \%)$ & $33(41.25 \%)$ \\
\hline Q13 & $3(3.75 \%)$ & $8(10 \%)$ & $14(17.5 \%)$ & $37(46.25 \%)$ \\
\hline Q16 & $0(0 \%)$ & $3(3.75 \%)$ & $18(22.5 \%)$ & $31(38.75 \%)$ & $28(35 \%)$ \\
\hline Q24 & $1(1.25 \%)$ & $1(1.25 \%)$ & $8(10 \%)$ & $21(26.25 \%)$ \\
\hline Q26 & $0(0 \%)$ & $12(15 \%)$ & $16(20 \%)$ & $49(61.25 \%)$ \\
\hline Q30 & $1(1.25 \%)$ & $1(1.25 \%)$ & $10(12.5 \%)$ & $38(47.5 \%)$ \\
\hline
\end{tabular}

\begin{tabular}{|c|c|c|c|c|c|}
\hline Manipulation & Never (0) & Hardly ever (1) & Sometimes (2) & Often (3) & Very Often (4) \\
\hline Q5 & $4(5 \%)$ & $12(15 \%)$ & $34(42.5 \%)$ & $20(25 \%)$ & $10(12.5 \%)$ \\
\hline Q6 & $40(50 \%)$ & $17(21.25 \%)$ & $16(20 \%)$ & $4(5 \%)$ & $3(3.75 \%)$ \\
\hline Q11 & $14(17.5 \%)$ & $15(18.75 \%)$ & $32(40 \%)$ & $14(17.5 \%)$ & $5(6.25 \%)$ \\
\hline Q12 & $16(20 \%)$ & $21(26.25 \%)$ & $21(26.25 \%)$ & $11(13.75 \%)$ & $11(13.75 \%)$ \\
\hline Q13 & $33(41.25 \%)$ & $18(22.5 \%)$ & $22(27.5 \%)$ & $3(3.75 \%)$ & $4(5 \%)$ \\
\hline Q19 & $44(55 \%)$ & $21(26.25 \%)$ & $11(13.75 \%)$ & $2(2.5 \%)$ & $2(2.5 \%)$ \\
\hline Q20 & $13(16.25 \%)$ & $13(16.25 \%)$ & $36(45 \%)$ & $12(15 \%)$ & $6(7.5 \%)$ \\
\hline Empathy & Never (0) & Hardly ever (1) & Sometimes (2) & Often (3) & Very Often (4) \\
\hline Q2 & $1(1.25 \%)$ & $11(13.75 \%)$ & $23(28.75 \%)$ & $28(35 \%)$ & $17(21.25 \%)$ \\
\hline Q3 & $2(2.5 \%)$ & $19(23.75 \%)$ & $35(43.75 \%)$ & $17(21.25 \%)$ & $7(8.75 \%)$ \\
\hline Q8 & $4(5 \%)$ & $14(17.5 \%)$ & $29(36.25 \%)$ & $25(31.25 \%)$ & $8(10 \%)$ \\
\hline Q9 & $0(0 \%)$ & $2(2.5 \%)$ & $29(36.25 \%)$ & $31(38.75 \%)$ & $18(22.5 \%)$ \\
\hline Q16 & $2(2.5 \%)$ & $3(3.75 \%)$ & $39(48.75 \%)$ & $25(31.25 \%)$ & $11(13.75 \%)$ \\
\hline Q17 & $1(1.25 \%)$ & $8(10 \%)$ & $39(48.75 \%)$ & $24(30 \%)$ & $8(10 \%)$ \\
\hline Q21 & $1(1.25 \%)$ & $7(8.75 \%)$ & $40(50 \%)$ & $25(31.25 \%)$ & $7(8.75 \%)$ \\
\hline Social Irritability & Never (0) & Hardly ever (1) & Sometimes (2) & Often (3) & Very Often (4) \\
\hline Q1 & $22(27.5 \%)$ & $23(28.75 \%)$ & $30(37.5 \%)$ & $4(5 \%)$ & $1(1.25 \%)$ \\
\hline Q4 & $11(13.75 \%)$ & $16(20 \%)$ & $42(52.5 \%)$ & $8(10 \%)$ & $3(3.75 \%)$ \\
\hline Q7 & $10(12.5 \%)$ & $14(17.5 \%)$ & $36(45 \%)$ & $13(16.25 \%)$ & $7(8.75 \%)$ \\
\hline Q10 & $18(22.5 \%)$ & $15(18.75 \%)$ & $35(43.75 \%)$ & $8(10 \%)$ & $4(5 \%)$ \\
\hline Q14 & $13(16.25 \%)$ & $17(21.25 \%)$ & $32(40 \%)$ & $15(18.75 \%)$ & $3(3.75 \%)$ \\
\hline Q15 & 32 (40\%) & 27 (33.75\%) & $16(20 \%)$ & $3(3.75 \%)$ & $2(2.5 \%)$ \\
\hline Q18 & $15(18.75 \%)$ & $20(25 \%)$ & $31(38.75 \%)$ & $8(10 \%)$ & $6(7.5 \%)$ \\
\hline
\end{tabular}

Table 3 showed the frequency and percentage of social intelligence among clinical occupational therapists. The social intelligence measured with Manipulation empathy social irritability (MESI) scale, it has three domains: manipulation has seven questions (Q5, Q6, Q11, Q12, Q13, Q19, Q20), empathy has seven questions (Q2, Q3, Q8, Q9, Q16, Q17, Q21), and social irritability has seven questions (Q1, Q4, Q7, Q10, Q14, Q15, Q18). There are 21 scaled questions ranging are $0=$ Never, $1=$ Hardly ever, 2 = Sometimes, 3 = Often, 4 = Very often. According to manipulation scoring, individuals who have higher scores in this domain can utilize others for their profit to do anything for their advantage. In the empathy factor, a higher score means that people can distinguish the intentions, weaknesses, and feelings of other individuals. Higher scores in the social irritability domain mean that individuals in this factor are worried while contacting other people. They also become anxious around individuals who are willing to do anything for them. In the manipulation domain, more than $48 \%$ of the participants agreed that they never use others for their benefit, whether it was to please them or not. In the empathy domain, none of the therapists does know how to act by the feelings of others. More than $47 \%$ of the participants agreed that they are sometimes able to guess the feelings of others even when they do not want to show, can guess the weaknesses of others, and can recognize people's intentions when contact with them. In the Social Irritability domain, more than $50 \%$ of therapists agreed that sometimes feelings of others baffle them.

Table 4 showed the frequency and percentage of the therapeutic relationship among clinical occupational therapist. The therapeutic relationship assessed in Scale to Therapeutic Relationship (STAR) consists of twelve questions and three domains 
Smily Jesu Priya Victor Paulraj et.al. Social intelligence, emotional intelligence and the therapeutic relationship among clinical occupational therapist.

which are positive collaboration has six questions (Q1, Q2, Q5, Q7, Q10, Q12), positive clinician input has three questions (Q 11, Q8, Q3), and emotional difficulties has three questions (Q4, Q6, Q9). The ranging of STAR scale is $0=$ never, $1=$ rarely, 2 = sometimes, 3 = often, 4 = always. In the positive collaboration domain, none of the participants rarely get well with his or her patient, rarely and never share a good rapport with the patient, and rarely believe he or she shared a good relationship with the patient. 50\% of the participants were often sharing a good rapport with their patients. In the positive clinician input domain, none of the therapists agreed that they never and rarely feel that they are supportive of their patients, never able to take their patients' perspective when working with them, and rarely listen to their patients. $67.5 \%$ of the participants agreed that they always feel that they are supportive of their patients. The highest percentage of agreement in this questionnaire is $73.75 \%$ which most of the participants were always listening to their patients. In the emotional difficulties domain, all of the therapists felt that their patient never rejects them as a clinician but $50 \%$ of them that they often been rejected as a clinician.

Table 4: Therapeutic relationship among Clinical Occupational Therapist

\begin{tabular}{|l|l|l|l|l|l|}
\hline Positive Collaboration & Never (0) & Rarely (1) & Sometimes (2) & Often (3) & Always (4) \\
\hline Q1 & $1(1.25 \%)$ & $0(0 \%)$ & $6(7.5 \%)$ & $39(48.75 \%)$ & $34(42.5 \%)$ \\
\hline Q2 & $0(0 \%)$ & $0(0 \%)$ & $7(8.75 \%)$ & $40(50 \%)$ & $33(41.25 \%)$ \\
\hline Q5 & $1(1.25 \%)$ & $0(0 \%)$ & $7(8.75 \%)$ & $36(45 \%)$ & $36(45 \%)$ \\
\hline Q7 & $2(2.5 \%)$ & $2(2.5 \%)$ & $29(36.25 \%)$ & $36(45 \%)$ & $11(13.75 \%)$ \\
\hline Q10 & $3(3.75 \%)$ & $9(11.25 \%)$ & $20(25 \%)$ & $27(33.75 \%)$ & $21(26.25 \%)$ \\
\hline Q12 & $0(0 \%)$ & $2(2.5 \%)$ & $6(7.5 \%)$ & $38(47.5 \%)$ & $34(42.5 \%)$ \\
\hline Positive Clinician Input & Never (0) & Rarely (1) & Sometimes (2) & Often (3) & Always (4) \\
\hline Q11 & $0(0 \%)$ & $1(1.25 \%)$ & $11(13.75 \%)$ & $32(40 \%)$ & $36(45 \%)$ \\
\hline Q8 & $0(0 \%)$ & $0(0 \%)$ & $4(5 \%)$ & $22(27.5 \%)$ & $54(67.5 \%)$ \\
\hline Q3 & $1(1.25 \%)$ & $0(0 \%)$ & $6(7.5 \%)$ & $14(17.5 \%)$ & $59(73.75 \%)$ \\
\hline Emotional Difficulties & Never (0) & Rarely (1) & Sometimes (2) & Often (3) & Always (4) \\
\hline Q4 & $0(0 \%)$ & $3(3.75 \%)$ & $6(7.5 \%)$ & $40(50 \%)$ & $31(38.75 \%)$ \\
\hline Q6 & $4(5 \%)$ & $6(7.5 \%)$ & $17(21.25 \%)$ & $15(18.75 \%)$ & $38(47.5 \%)$ \\
\hline Q9 & $3(3.75 \%)$ & $5(6.25 \%)$ & $22(27.5 \%)$ & $22(27.5 \%)$ & $28(35 \%)$ \\
\hline
\end{tabular}

Table 5: Social intelligence, emotional intelligence domains and therapeutic relationship among Clinical Occupational therapist

\begin{tabular}{|l|l|l|l|}
\hline Emotional intelligence domains & $\boldsymbol{n}$ & $\boldsymbol{r}$ & $\boldsymbol{p}$ \\
\hline Managing other emotions & 80 & 0.47 & 0.00001 \\
\hline Managing own emotions & 80 & 0.41 & 0.00019 \\
\hline Perception of emotion & 80 & 0.47 & 0.00001 \\
\hline Utilization of emotion & 80 & 0.17 & 0.14248 \\
\hline Social intelligence scale domains & $\boldsymbol{n}$ & $\boldsymbol{r}$ & $\boldsymbol{p}$ \\
\hline Manipulation questions & 80 & 0.08 & 0.49265 \\
\hline Empathy & 80 & 0.32 & 0.00361 \\
\hline Social irritability & 80 & -0.25 & 0.02587 \\
\hline
\end{tabular}

Table 5 showed that correlation among social intelligence, emotional intelligence and therapeutic relationship among clinical occupational therapist. The analysis of each domain in emotional intelligence revealed that managing other emotions $(r=0.47, p=0.00001)$, managing own emotions $(r=0.41, p=0.00019)$, and perception of emotion $(\mathrm{r}=0.47, \mathrm{p}$ $=0.00001$ ) showed moderated positive correlation on therapeutic relationship and statistically significant. Whereas the utilization of emotion showed a very weak positive correlation on the therapeutic relationship and not statistically significant. Furthermore, the analysis of domains in social intelligence revealed that manipulation domains showed very weak positive correlation and not statistically significant ( $r=0.08, p=0.49265)$, empathy showed weak positive correlation and statistically significant $(\mathrm{r}=0.32, \mathrm{p}$ $=0.00361$ ), and social irritability showed weak negative correlation and not statistically significant $(r=-0.25, \quad p$ $=0.02587$ ).

Table 6: Social intelligence, emotional intelligence and the therapeutic relationship

\begin{tabular}{|l|l|l|l|}
\hline Scales & $\boldsymbol{n}$ & $\boldsymbol{r}$ & $\boldsymbol{p}$ \\
\hline Emotional intelligence & 80 & & \multirow{2}{*}{0.43} \\
\cline { 1 - 2 } Social intelligence & 80 & 0.00006 \\
\cline { 1 - 2 } Therapeutic relationship & 80 & & \\
\hline
\end{tabular}

Table 6 analysis the relationship between social intelligence, emotional intelligence and therapeutic relationship among clinical occupational therapist. Pearson correlation coefficient analysis used 
Smily Jesu Priya Victor Paulraj et.al. Social intelligence, emotional intelligence and the therapeutic relationship among clinical occupational therapist.

for analysis. The findings reported that there was a moderate positive correlation ( $\mathrm{r}$ $=0.43$ ) between socio intelligence, emotional intelligence and therapeutic relationship among clinical occupational therapist. The p-value showed there was a significant difference $\mathrm{p}=0.00006$.

\section{DISCUSSION}

This study conducted to determine the relationship between social intelligence, emotional intelligence and therapeutic relationship among clinical occupational therapists. Based on Table 1, which showed demographic data of the participants, only 80 participants were agreed to participate in this study. Most of the participants, 69 of them, had the lower years of experience of clinical OT criteria. About 61 females and 19 males were a participant in this study. The numbers of females were more significant than males because of the high level of motivation that females have to join the study, and also because males were excusing that they had a time barrier which prevents them from participation in research.

The study showed that emotional intelligence among the clinical occupational therapists of this research which divided into four different domains, statistically customarily distributed (Table 2). This research found that the perception of emotions, regulating their own emotions, utilization of emotion, and managing others' emotion was high in all of the therapists. The present study showed that therapists have the ability to show their one's own and others' feelings and emotions, to differentiate among them and to use this information to guide one's thinking and actions which make easier to transfer effective emotional abilities into the realm of treatment. The previous study indicated that therapists with higher emotional intelligence had better therapist-rated outcome results (Kaplowitz, Safran, \& Muran, 2011). Clinical OTs showed high scores on social intelligence's domains, which were manipulation, empathy, and social irritability (Table 3). This means that they have the ability to percept precisely, appraise and express their own emotions to their patients and understanding them and generate feelings when they facilitate thinking, as well as regulate and utilize emotions in problem-solving. They are also understanding the person's sensitive behaviors and their personalities when dealing with a patient in order to build a meaningful relationship and set goals and plans.

In this study, it shown that clinical OTs had high scores in therapeutic relationship questionnaires, which its domains were a positive collaboration, positive clinician input, and emotional difficulties (Table 4). The high scoring of TR indicated that OTs have a close and consistent relationship with their clients which encourages them to share their intimate thoughts, beliefs, and emotions regarding the issues in question while receiving treatment. According to another study stated that positive therapeutic relationship ratings between physical therapists and patients are associated with improvements in treatment outcomes (Ferreira, Ferreira, Maher, Refshauge, Latimer \& Adams, 2012).

Additionally, another finding of the research found out that there was a different level of correlation between each domain of EI and SI and the therapeutic relationship. In EI domains, managing other emotions, managing own emotions, and perception of emotion showed that there is a moderated positive correlation on the therapeutic relationship and statistically significant. However, utilization of emotion showed a very weak positive correlation on the therapeutic relationship and not statistically significant. This means that therapists remain open and receptive about his/her own emotions, and they able to predict the emotional reactions and responses of their clients. Previous research is also found that the therapist's aware about the situation and how to react accordingly to the clients' feelings. In SI domains, manipulation 
Smily Jesu Priya Victor Paulraj et.al. Social intelligence, emotional intelligence and the therapeutic relationship among clinical occupational therapist.

domains showed a very weak positive correlation and not statistically significant, empathy showed weak positive correlation and statistically significant, and social irritability showed weak negative correlation and not statistically significant. Even though this finding showed that empathy is the only domain that has statistical significance with $\mathrm{TR}$, it was positively related to the TR. The social irritability domain was the only domain that did not have any relationship with TR. Early research found that irritability is an excessive reactivity to negative emotional stimuli and describes it as having an affective component, anger, and a behavioral component, aggression (Leibenluft \& Stoddard, 2013). However, because irritability predicts suicidality, social impairment, and depressive and anxiety disorders in adulthood, a negative correlation between social irritability and TR indicated that therapists had a great positively therapeutic relationship with their patients.

This study found that there was a significant difference between gender and TR. Female $(P=0.004)$ indicated more score of TR domain than male $(\mathrm{P}=0.233)$ did. This finding is supported by many studies that concluded that TR between females' therapists and their clients are stronger than the males' therapists, which resulted in better outcomes. However, in this study, this statement could be influenced by the sample's number of females $(n=61)$ and male $(n=19)$. Because the number of females that joined the study was higher than the male, we cannot correctly conclude the effect of gender on TR. Besides, there was a relationship between age and social intelligence. This study showed that therapists with 0 to 5 years of experience had strong TR with their clients rather than older ones and affected by the numbers of the sample from each year of experience grouping. The number of participants with 1 month to 5 years of experience was $69(\mathrm{P}=0.00013)$, whereas the remaining 11 participants $(\mathrm{P}=0.71)$ were distributing between the other three groups (Table 1). This number of participants among each group can affect this finding. However, this statement can be correct because, as experience increased, most of the therapists believe that they know the client more than he or she does because they were facing many conditions that similar to the client's condition. The analysis of the relationship between social intelligence, emotional intelligence and therapeutic relationship among clinical occupational therapists showed that there is a significant difference $(p=0.00006)$ between them (Table 6). Therefore, having excellent social intelligence, emotional intelligence affects the therapeutic relationship positively.

The findings of this study have some limitations. There were difficulties in getting the exact sample size and the researcher excluded interns from the sample size. In the future, when a similar study conducted again, they need to include the interns as well. The future recommendation for clinical occupational therapists to increase their awareness of social intelligence, emotional intelligence and its importance or impact on the therapeutic relationship by providing them credit hours courses about emotional intelligence and social intelligence meaning, impact, and importance. Giving the therapists two to five individual coaching hours which would expand their mindset in many variables such as, problem-solving, communication, and may make them think form other perspectives which eventually will increase their performance with their clients and control their empathy. Another recommendation is providing some facilitation programs training, some workshops. Also, giving an evaluation form for the client after taking a session with the occupational therapist to evaluate the performance of the therapist, and what went perfectly, good, neither good nor bad, bad, and worst. In the end, to find if these recommendations were making positive impacts on the therapists and their clients, 
Smily Jesu Priya Victor Paulraj et.al. Social intelligence, emotional intelligence and the therapeutic relationship among clinical occupational therapist.

we recommend re-evaluating the socioemotional intelligence and the therapeutic relationship among clinical occupational therapists.

\section{CONCLUSION}

The study found that there was relationship between SI, EI therapeutic relationship in a clinical occupational therapist. Furthermore, the study found there were significant differences in age and gender between the same variables. This study found that novice occupational therapist has better EI and SI hence good therapeutic relationship with patients which enhance treatment plan. The clinical implication for occupational therapy to increase the visits to the prior hospital graduation may maximize students' opportunities to apply their academic knowledge in clinical scenarios utilizing clients that are unfamiliar to them, real-life clients, if possible, and simulation labs (Callen, 2018). Increasing EI and SI will strengthen the therapist's empathic expertise. When an occupational therapist understands the client's needs, they can build a therapeutic relationship. It may also promote therapeutic use of self. Understanding one's own and others' emotions requires EI and SI. Occupational therapists need to be trained in SI and EI. We must provide EI and SI training to new occupational therapists before clinical practice. Giving EI and SI training to current occupational therapists will improve rehabilitation outcomes.

Acknowledgement: None

\section{Conflict of Interest: None}

\section{Source of Funding: None}

\section{Ethical Approval: Approved}

\section{REFERENCES}

1. Ardito R, Rabellino D (2011). Therapeutic Alliance and Outcome of Psychotherapy: Historical Excursus, Measurements, and Prospects for Research. Frontiers in Psychology. 2.
2. Akerjordet, K., \& Severinsson, E. (2007). Emotional intelligence: A review of the literature with specific focus on empirical and epistemological perspectives. Journal of Clinical Nursing, 16, 1405-1416.

3. Birks, Y. F., \& Watt, I. S. (2007). Emotional intelligence and patient-centered care. Journal of the Royal Society of Medicine, 100, 368-374.

4. Callen, J. (2018). Therapeutic Relationship in Theory and Practice. Available from: https://soar.usa.edu/cgi/viewcontent.cgi?arti cle $=1001 \&$ context $=$ ot

5. Chou w. Social Intelligence vs. Emotional Intelligence: What's the Difference? [Online]. Medium. 2016 [Cited: 9 February 2019]. Available from: https://medium.com/personal-developmentsuccess/social-intelligence-vs-emotionalintelligence-whats-the-difference7c759365127b

6. Cherry K. 9 Signs of Low Emotional Intelligence [Online]. Verywellmind.com. 2018 [Cited: 1 December 2018]. Available from: https://www.verywellmind.com/signsof-low-emotional-intelligence-2795958.

7. Cherniss, C. (2002). Emotional intelligence and the good community. American Journal of Community Psychology, 30, 1-11.

8. Duggal N. Emotional Intelligence in the Workplace: Why You Need It, how to Get It [Online]. Simplilearn.com. 2019 [Cited: 9 January 2019]. Available from: https://www.simplilearn.com/emotionalintelligence-what-why-and-how-article.

9. Ferreira H, Ferreira M, Maher, Refshauge, Latimer \& Adams (2012). The Therapeutic Alliance Between Clinicians and Patients Predicts Outcome in Chronic Low Back Pain. Physical therapy. 93. 10.2522/ptj.20120137.

10. Frankovsky M, Birknerova Z. Measuring Social Intelligence-The MESI Methodology. Asian Social Science [Online]. 2014 [Cited: 3 March 2019];10(6):90-97. Available from: http://www.ccsenet.org/journal/index.php/as s/article/view/34666.

11. K. Fedders L. The Importance of the Relationship with the Therapist. Clinical Science Insights: Knowledge Families Count On. 2008; v.1

12. John D. Mayer P. Emotional Intelligence. 1st ed. New Haven: PETER SALOVEY and JOHN D. MAYER; 2019. 
Smily Jesu Priya Victor Paulraj et.al. Social intelligence, emotional intelligence and the therapeutic relationship among clinical occupational therapist.

13. Jacuqui M, Jo-anne W. Emotional Intelligence and the Occupational therapist. [Online]. 2013 [Cited: 27 January 2019]. Available from: https://www.researchgate.net/profile/Jacqui _Mckenna/publication/269970361_Emotion al_Intelligence_and_the_Occupational_Ther apist/links/568bbb6408ae1e63f1fdd771/Em otional-Intelligence-and-the-Occupational Therapist.pdf?origin=publication_detail.

14. Kaplowitz M, Safran J, Muran C. Impact of Therapist Emotional Intelligence on Psychotherapy. The Journal of Nervous and Mental Disease. 2011;199(2):74-84.

15. Leibenluft E, Stoddard J. The developmental psychopathology of irritability. Development and Psychopathology. 2013;25(4pt2):14731487.

16. Muran J, Barber J. The therapeutic alliance. New York: Guilford Press; 2010.

17. McGUIRE-SNIECKUS, R., McCABE, R., Catty, J., Hansson, L. and PRIEBE, S. (2006). A new scale to assess the therapeutic relationship in community mental health care: STAR. Psychological Medicine, 37(01), p.85.

18. Salovey, P. \& Mayer, J. (1990). Emotional intelligence. Imagination, Cognition, and Personality, 9, 185-211.

19. Petrides, K. V. Psychometric properties of the Trait Emotional Intelligence Questionnaire (2009). In C. Stough, D. H. Saklofske, and J. D. Parker, Advances in the assessment of emotional intelligence. New York: Springer.

20. Petrides, K. V., \& Furnham, A. (2001). Trait emotional intelligence: Psychometric investigation with reference to established trait taxonomies. European Journal of Personality, 15, 425-448.

21. Petrides, K. V., \& Furnham, A. (2003). Trait emotional intelligence: Behavioural validation in two studies of emotion recognition and reactivity to mood induction. European Journal of Personality, 17, 39-57.

22. Petrides, K. V., Niven, L., \& Mouskounti, T. (2006). The trait emotional intelligence of ballet dancers and musicians. Psicothema, 18, 101- 107.

23. Petrides, K. V., Pita, R., \& Kokkinaki, F. (2007). The location of trait emotional intelligence in personality factor space. British Journal of Psychology, 98, 273-289.

24. Peloquin, S. (1990). The Patient-Therapist Relationship in Occupational Therapy: Understanding Visions and Images. American Journal of Occupational Therapy, 44(1), pp.13-21.

25. Pendleton H, Schultz-Krohn W. Pedretti's occupational therapy. 7th ed. St. Louis, Missouri: Elsevier/Mo Petrides, K. V. Psychometric properties of the Trait Emotional Intelligence Questionnaire (2009). In C. Stough, D. H. Saklofske, and J. D. Parker, Advances in the assessment of emotional intelligence. New York: Springer.

How to cite this article: Paulraj SJPV, Alaboudi SF, Mali RM et.al. Social intelligence, emotional intelligence and the therapeutic relationship among clinical occupational therapist. Int J Health Sci Res. 2021; 11(11): 275-285. DOI: https://doi.org/10.52403/ijhsr. 20211133 